\title{
Blogosfera cubana: um novo espaço público para a construcão de uma sociedade plural e cidadã
}

\section{RESUMO}

A reflexão sobre o ciberespaço na reconfiguração da esfera pública, a partir dos blogs cubanos como práticas democráticas na construção da cidadania, considerou seis blogs de internautas cubanos encontrados na rede. A análise de suas narrativas nos permitiu verificar a recuperação do sentido de ser cidadão através da participação e da livre manifestação dos internautas cubanos, pois, os blogs são espaços que possibilitam o diálogo sobre temas de interesse público. Através do acesso, da interatividade e da conexão em rede, as mídias digitais permitem novas práticas culturais, ampliando e fortalecendo os laços de pertencimento entre cidadãos com interesses comuns, favorecendo a troca de informações entre os grupos locais e globais. Assim, as práticas comunicativas dos blogs desempenham o papel de mediadores na construção da cidadania.

\section{PALAVRAS-CHAVE}

Ciberespaço

Cidadania

Blogs cubanos

Cuban blogosphere: a new public space for the construction of a plural and citizen society

\section{ABSTRACT}

The reflection on cyberspace in the reconfiguration of public sphere, taking Cuban blogs as democratic practices in construction of citizenship, considered six Cuban blogs found on the web. The analysis of these blogs' narratives allowed us to verify the recovery of the citizenship sense through the participation and free expression of the Cuban bloggers, because the blogs are spaces which enable the dialogue of themes of public interest. Through access, interactivity and net connection, the digital media allow new cultural practices, broadening and strengthening the belonging ties among citizens with common interests, favoring information exchange between local and global groups. Therefore, the communicational practices of blogs perform a roll of mediation in citizenship construction.

\section{KEYWORDS}

Cyberspace

Citizenship

Cuban blogs

\section{Lia Luz}

Doutoranda em Ciências Sociais pela UFRN/RN/BR

liahluz@gmail.com

\section{Valdir José Morigi}

Professor do Programa de Pós-Graduação em Comunicação e Informaç̃o da UFRGS/RS/BR

valdir.morigi@ufrgs.br

A imprensa é considerada um dos principais espaços da modernidade no qual o cidadão pode exercer seu direito de receber informação e manter-se informado. Entretanto, no caso de regimes totalitários, nos quais pode ser incluída a República Socialista de Cuba, com partido único e sem eleições diretas para cargos executivos, inexiste uma imprensa livre e, portanto, fica comprometido o direito de participação do cidadão e de manter-se constantemente informado.

A eclosão do ciberespaço, aos poucos, está ajudando a mudar essa realidade, quebrando o monopólio das vozes oficiais naquele país. Enquanto no mundo inteiro tal fenômeno apenas prossegue um movimento plurissecular de incremento da transparência, no caso de Cuba se reveste de fundamentais singularidades.

\section{O ciberespaço permife aos cubanos não apenas exercer - ainda que de forma tímida, em razão de diversos}




\section{mecanismos ligados d̀ censura, como o elevado preço de acesso à Internet e o bloqueio, dentro da ilha, à visita de alguns sifes - o direito de manferem-se informados, mas também 0 de livre expressão'.}

As práticas comunicativas dos blogs mantidos por cubanos, através das listas de discussões e comentários, configuram-se em espaços públicos. Neles podem ser divulgadas ideias, informações e manifestações pessoais que não teriam abrigo na imprensa oficial. O exercício da liberdade de expressão de cidadãos comuns possibilita a ampliação do debate, elemento fundamental na construção de uma sociedade plural e democrática. E o fato de os blogueiros citarem, em suas páginas, textos publicados nos blogs de outros colegas mostra que tais práticas comunicativas estão se constituindo numa rede cidadã, o que nos permite aferir sua eficiência em formar a ação dialógica fundamental para a construção de esfera pública.

Neste artigo, indagamos: como a prática dos blogs (re)criam o espaço público, possibilitando o exercício da cidadania e como tal prática através dos blogs pode ampliar a participação e a livre expressão dos cidadãos em Cuba, examinando o desempenho desse papel pelos blogs?

A busca das respostas partiu do blog Generación $\mathrm{Y}^{2}$, o mais conhecido e acessado entre os escritos desde a ilha. Na página mantida pela filóloga cubana Yoani Sánchez, estão listados diversos espaços similares, nos quais jornalistas independentes, com ou sem formação na área, expressam suas opiniões sobre o país. $\mathrm{Na}$ segunda etapa da pesquisa, realizada em janeiro e fevereiro de 2010, visitamos os endereços referenciados por Sánchez. Da lista, foram excluídos os blogs desatualizados. Por fim, para reduzi-lo a cinco endereços, priorizamos aqueles com maior periodicidade, número de acessos ou caráter jornalístico e de denúncia.

$\mathrm{Na}$ análise do corpus, partimos do pressuposto que os processos de criação dos blogs e de produção e de mediação dos seus conteúdos informativos reconfiguram a esfera pública, possibilitando aos cubanos, à margem da imprensa oficial, exercitar seu papel cidadão. Partimos da concepção de cidadania proposta por T. H. Marshall (1967), e para refletir sobre o processo histórico de constituição do espaço público buscamos o modelo denominado de "tradição republicana" de Hannah Arendt (1974; 1981). Para compreender como a esfera pública se reconfigura no ciberespaço, nos apoiamos no pensamento de Pierre Lévy (2002).

\section{A (re)estrufuração da esfera pública e a refomada de práticas cidadãs na blogosfera cubana}

Entre as diversas interpretações da cidadania, tornouse hegemônica a concepção liberal, apoiada na visão político-jurídica "de direito a ter direitos", conforme a tipologia (direitos civis, políticos e sociais) criada por $\mathrm{T}$. H. Marshall, que, analisando o caso inglês, generalizou a noção de cidadania e de seus elementos constitutivos (Marshall, 1967). Conforme essa perspectiva, a cidadania seria composta dos direitos civis e políticos - mais tarde denominados por Bobbio (1992) de direitos de primeira geração -, e dos direitos sociais - os de segunda geração.

Os direitos civis, conquistados no século XVIII, correspondem aos direitos individuais de liberdade, de ir e vir, direito à vida, à segurança, sendo aqueles que embasam a concepção liberal de cidadania. Já os direitos políticos, alcançados no século XIX, relacionam-se à liberdade de associação de reunião, de organização política e sindical, ao sufrágio universal etc. Também chamados de direitos individuais exercidos coletivamente, acabaram se incorporando à tradição liberal. Os direitos sociais, econômicos ou de crédito, da segunda geração, foram conquistados no século XX. São os direitos ao trabalho, à saúde, à educação, enfim, àqueles que garantem acesso aos meios de vida e bem-estar social e tornam reais os direitos formais.

Cada Estado-nação atribuirá maior ou menor peso para uma determinada geração desses direitos, de acordo com a tradição e o regime adotado (Vieira, 2001). No contexto de Cuba, uma república socialista totalitária, há uma prerrogativa dos direitos sociais em detrimento dos civis e políticos, uma vez que os cubanos não elegem os seus representantes e tampouco gozam de liberdade para deixar a ilha. Em contrapartida, contam com um sistema de saúde e de educação considerado modelo, apesar da situação econômica cada vez mais delicada em que o país foi mergulhando com a perda do apoio 
financeiro da ex-URSS, ao final da década de 1980.

$\mathrm{Na}$ atualidade, as principais correntes do pensamento político conferem centralidade ao papel do direito e da cidadania na construção de um Estado democrático, exigindo uma sociedade aberta para permitir a ampliação e a criação de novos direitos. Na concepção de Arendt (1981), a história do mundo moderno, poderia ser descrita como a história da dissolução desses espaços públicos de luta e de debate, pelos quais se expressava "um sentido cidadão de participação" e através dos quais os homens podiam se reconhecer, compartilhando um destino comum.

A perda dessa esfera pública de tradição republicana significa também a dissolução desse mundo comum, comprometendo a capacidade de discernimento que a compreensão e o julgamento exigem, enquanto "maneira especificamente humana" de se fazer a experiência da realidade (Telles, 1990). Realidade esta que resulta de uma construção dependente da forma específica de sociabilidade unicamente instituída pelo espaço público: a pluralidade. Sem o espaço público, portanto, os homens tornam-se, no entender de Arendt, prisioneiros da subjetividade de sua própria existência singular.

$[\ldots]$ os homens tornam-se inteiramente privados, isto é, privados de ver e ouvir os outros e privados de ser vistos e ouvidos por eles. São todos prisioneiros da subjetividade de sua própria existência singular, que continua a ser singular ainda que a mesma experiência seja multiplicada inúmeras vezes. (Arendt, 1981, p. 67)

Assim, segundo Arendt, a realidade do mundo só pode se manifestar "de maneira real e fidedigna" quando as coisas podem ser vistas por muitas pessoas, numa variedade de aspectos, de maneira que os que estão a sua volta sabem que veem a mesma coisa, na mais completa diversidade (Telles, 1990; Arendt, 1981). É a esfera pública, portanto, a construtora desse mundo comum entre os homens, mundo tal que tem de ser pensado não apenas como aquilo que é comum, mas como aquilo que é comunicável.

Entendendo o espaço público como local para construção de um mundo comum, como um espaço mediador que separa e estabelece uma relação entre os indivíduos, qualquer lugar pode se tornar espaço público quando se torna espaço de poder, de ação comum coordenada por meio do discurso. De acordo com essa concepção, os blogs mantidos por jornalistas independentes em Cuba também são espaços de mediação discursiva e de retomada do exercício da cidadania.

\section{Na modernidade, a prática cidadã não se restringe apenas ao exercício de direitos e deveres do cidadão em relação ao Estado, contemplando também a aparição desses indivíduos no espaço público como sujeifos de demanda e proposição em relação aos diversos âmbitos de suas experiências.}

"Por isso, as reflexões sobre a condição cidadã como condição necessária para a democracia resulta limitada se não se relaciona com essa nova característica do espaço público." (Mata, 2006, p. 8).

Em face da importância das mídias na atualidade, a autora considera válida a articulação comunicaçãocidadania, remetendo, de um lado, aos direitos civis de liberdade de expressão, e, de outro, recuperando o conceito republicano de cidadania, que "[...] associa o exercício cidadão ao compromisso das pessoas com a coisa pública", estando relacionado ao compromisso do cidadão na construção coletiva de projetos de sociedade (Hopenhayn, 2005, p. 215; Mata, 2006). Essa construção plural, no entanto, sofre limitações, conforme coloca Garretón (1995, p. 105):

A grande contradição contemporânea é que a multiplicidade de possibilidades de constituição de sujeitos se enfrenta, entretanto, na apropriação - por parte de algumas nações, Estados, empresas, instituições, atores - dos instrumentos que permitem dita constituição, como a riqueza, os conhecimentos, o poder, a expressividade do subjetivo, a afetividade e a comunicabilidade. 
Esta apropriação, pelo governo cubano, da comunicabilidade, ou seja, da mídia tradicional, aos poucos começa a ser modificada através da prática dos blogs, usados como ferramentas de mediação e de visibilidade, de crítica da realidade social e de reivindicação de direitos. De forma que, se, por um lado, conforme pensava Arendt, na modernidade, houve uma oclusão do político pela ascensão do social, resultando o declínio da esfera pública, por outro, com o ciberespaço, parece ocorrer fenômeno oposto: multiplicam-se os espaços possibilitando a mediação discursiva, ampliando o espaço público para o debate e a experiência da pluralidade. "Esta mutação da esfera pública constituiu um dos fundamentos da ciberdemocracia". (Lévy, 2002, p. 56).

Segundo o autor,

\section{permitir aos indivíduos expressarem-se livremente, sem ferem de passar pelo poder do jornalismo ou pela censura do governo, é a principal vanfagem da Internet frente à mídia tradicional.}

Como resultado, a esfera pública se alarga e se diversifica. As mídias digitais trazem impactos na rede de sociabilidade, bem como na construção do mundo comum, através da formação de redes interativas (comunidades virtuais), ao realizarem a mediação de sentidos que são disseminados na rede entre os cidadãos que acessam tais artefatos.

Com as mídias, é toda concepção de política, de cidadania e de relação entre subjetividade e mundo social que se transfigura. [...] as mídias digitais transformaram a organização espacial e temporal da vida social, criando novas formas de ação, de interação e de exercício do poder. (Floriani; Morigi, 2006, p. 108)
Ao se configurarem como espaços para compartilhamento de significações, as mídias digitais não ampliam apenas a prática cidadã, permitindo, a partir do diálogo e da pluralidade, a construção de uma histórica comum, mas também a noção de democracia, considerando que o estado democrático reserva centralidade ao papel da cidadania. Os blogs mantidos por jornalistas independentes de Cuba são um exemplo dessa (re)estruturação da esfera pública no ciberespaço, como práticas democráticas na construção da cidadania. A seguir, listamos e descrevemos cinco deles, considerando o perfil dos seus criadores e os conteúdos veiculados em cada um.

Generación Y-Mantido pela filóloga Yoani Sánchez, é hoje o mais conhecido entre os escritos desde Cuba, sendo inspirado em pessoas como ela própria, ou seja, nascidos na ilha nos anos 1970 e 1980 e "marcados por las escuelas al campo, los muñequitos rusos, las salidas ilegales y la frustración" ${ }^{3}$. Acompanhado por internautas mundo afora e com fama internacional, tem seu acesso bloqueado dentro da ilha. Entre as temáticas publicadas, destacam-se: relatos sobre a situação atual de Cuba, contraposta aos números e às informações divulgadas pelo Partido; o fortalecimento do grupo de blogueiros e a importância do trabalho por eles desenvolvido; e os casos de repressão sofridos por ela própria e por outros cubanos.

Ancla Insular ${ }^{4}$ - Foi criado pelo escritor, historiador e jornalista independente Miguel Iturría Savón para trocar resenhas literárias e culturais, crônicas, artigos e opinião sobre Cuba e outros sites. Entre as temáticas, estão desde resenhas de filmes diversos e notícias de agenda cultural aos desabafos sobre a manipulação das informações pela imprensa oficial e sobre como os cubanos estão praticamente de mãos atadas, em razão de os que estão no poder se apropriarem, também, dos meios de comunicação e das forças produtivas. Entretanto, num dos posts, ele lembra que, apesar do alto custo de acesso à Internet, os blogueiros conseguem oferecer uma visão mais autêntica do que ocorre atrás da cortina de fumaça do castrismo.

Cuba en Blanco y Negro5 - Uma visão de Cuba como ela é, sem distorções. Com caráter de denúncia, expõe as mazelas do sistema de saúde da ilha, afirmando ser tolice acreditar numa invasão americana como 
justificativa às restrições de liberdade impostas. $\mathrm{O}$ blog também recorda da distinta condição de vida dos membros do partido, que podem comprar roupas com preços 20 vezes maiores que o salário médio de 20 dólares no país. Como os demais, também enaltece a iniciativa dos blogueiros, lembrando que as mídias digitais formam uma máquina que não pode ser controlada, como o é a imprensa oficial no país.

Desde aquí6 - Mantido pelo jornalista Reinaldo Escobar, foi criado pela necessidade pessoal de escrever temas que rondam sua cabeça, mas que não encontram espaço nos meios oficiais cubanos. Em tom de denúncia, retoma a ideia de que o discurso oficial, emitido pelos meios de comunicação e pelas instituições culturais, está distante da realidade. Lembra que os jornalistas independentes e a incipiente blogosfera alternativa cubana cumprem, de forma admirável, a missão de informar sobre o estado de uma realidade compartilhada pela maioria. Também toca na questão da existência de uma elite cubana, formada pelos governantes, e na falta de liberdade de ir e vir da população.

Sin EVAsión7 - É mantido, há mais de dois anos, por Miriam Celaya, cidadã de Havana pertencente a uma geração que tem vivido debatendo-se entre a ilusão e a esperança, e cujos membros alcançaram a maioridade no controvertido ano de 1980. Em julho de 2008, ela, que atuava sob o pseudônimo de Eva, assumiu publicamente sua verdadeira identidade. Nas páginas, faz referência a outros blogueiros, e inclusive anuncia a chegada de mais um deles, reforçando o caráter sui generis do fenômeno blogger, contestatório e rebelde por natureza. No último post de 2009, com data de 28 de dezembro, faz um balanço da blogosfera alternativa, assistindo sua multiplicação.

Os blogs possuem finalidades semelhantes: a de se constituírem em espaços de crítica à realidade social e de reivindicação de direitos, de liberdade de expressão, troca de opiniões e dialogicidade. Funcionam como uma válvula de escape simbólica para o discurso antes preso nas garras da censura, adquirindo centralidade como cena privilegiada de trocas. Frequentemente, os próprios blogueiros ressaltam a importância de se organizaram em rede, para fortalecerem a experiência de construírem uma visão de mundo diferente daquela expressa nos discursos oficiais. E é essa pluralidade de visões de mundo que garante, segundo defende Arendt, a construção do mundo comum.

Os blogueiros contestam as informações oficiais, denunciam a falta de liberdade de expressão, a ação dos aparelhos repressivos do Estado, a manipulação da imprensa e expõem as mazelas da vida cotidiana, decidindo o que publicar na rede, conforme expressa a própria Yoani Sánchez.

Me atrevería a decir que las autoridades no
se imaginaban que los ciudadanos apelarí-
an a un recurso planetario para expresarse.
El gobierno controla las cámaras de los es-
tudios de televisión, los micrófonos de las
estaciones de radio, las páginas de revistas
y periódicos que se localizan en el territorio
insular, pero allá arriba, lejos de su alcance,
una red satelital - satanizada pero impres-
cindible - ofrece a quien se lo proponga la
posibilidad de 'colocar' sus opiniones de
forma prácticamente ilimitada.

Les llevó tiempo comprenderlo, pero se están dando cuenta. Ya saben que para silenciar a un blogger no pueden usar los mismos métodos que lograron acallar a tantos periodistas. A estos impertinentes de la web nadie puede despedirlos de la redacción de un diario, ni prometerles una semana en Varadero o un auto Lada como compensación, mucho menos podrían captarlos con un viaje a Europa del Este. A un blogger, para anularlo, hay que eliminarlo o intimidarlo y esa ecuación ha comenzado a entenderla el estado, el partido [...] el General (2010). ${ }^{8}$

O último parágrafo do texto é uma referência ao ataque por ela sofrido, em novembro de 2009, quando foi detida, de forma agressiva, por agentes de segurança, ao pretender participar de uma manifestação contra a violência. $O$ episódio, de repercussão internacional, recebeu mais de mil comentários na página de Yoani, e também ecoou por pelos menos outros dois blogueiros da ilha, demonstrando que os blogs são espaços que possibilitam o diálogo, além de se constituírem fóruns de discussão sobre temas diversos, moldando a opinião pública.

No Ancla Insular, Miguel Iturría Savón (2010) afirma:

Mi amiga, como yo y tantos cubanos, piensa en los cambios democráticos que requiere nuestra isla [...]. Mi amiga es filóloga y tiene 34 años. Ha recibido premios internaciona- 
les por su blog, pero en Cuba es denigrada por la prensa oficial y fue golpeada en plena vía pública por orden de un Comandante reciclado en general. Su esposo también fue apaleado en la calle más céntrica de La Habana. ${ }^{9}$

O texto de Savón, reverberando sua indignação em relação aos mecanismos de repressão e de censura, ilustra a sociabilidade emergente nas mídias sociais, onde são criadas redes interativas (comunidades virtuais) por sujeitos unidos num objetivo comum, no caso o de compartilhar informações e exercitar a liberdade de expressão através de práticas cidadãs. Ele argumenta que esses amigos blogueiros escrevem seus posts sem pensar na repressão e nos membros do partido, comentando a realidade omitida ou distorcida pelos comunicadores oficiais.

Essa interconexão entre os blogueiros também se expressa no texto que segue, quando o blog Cuba em Blanco y Negro, de autoria anônima, posta o seguinte comentário a respeito do ocorrido:

Menudo impacto tuvo en mí conocer que habían golpeado a Yoanis y otros compatriotas de la blogosfera cubana, rabia, indignación, y deseos de arrancarle la cabeza a alguien como en las películas de horror. Lo que le pasó a Yoanis fue un disparate y de los grandes. No fue sólo una acción en contra de un ser humano, fue además una amenaza contra la libertad de expresión de nosotros los cubanos. Fue un intento de acallar la voz que hace doler sus heridas. No creo que puedan callar a Yoanis. No creo que puedan con ella, no creo que puedan con nosotros. ${ }^{10}$

Conforme percebemos, o blog reforça essa noção de rede, de comunidade integrada, que toma para si, coletivamente, as dores de uma ação endereçada a um indivíduo em particular, porque, afinal, ela agride o objetivo comum. A ideia expressa é que os blogueiros são como um ente só na luta pela liberdade de expressão. Nesse sentido, tentar silenciar uma das vozes que constroem a pluralidade da blogosfera cubana teria um efeito contrário, fazendo diversas outras falarem para defender quem foi calado e, assim, manter pujante a batalha pela conquista do bem comum, do direito de informar e manter-se informado.
Segundo Lévy (2002, p. 53), “[...] as pessoas que frequentam várias comunidades virtuais fazem passar, de uma para outra, as informações que consideram pertinentes" de maneira que é possível pensar a possibilidade de transformação do mundo social a partir da organização dos indivíduos/blogueiros em redes, expressando antagonismos e modificando a representação do mundo que contribui para a sua própria realidade. Desta forma, no ciberespaço, por meio da prática dos blogs, se reconfigura a esfera pública através da participação dos cidadãos, pois se torna possível o exercício da cidadania, fortalecendo o sentimento de pertença ampliado pela organização dos grupos articulados em redes conectadas que medeiam a produção dos conteúdos informativos veiculados nos ambientes virtuais. Sobre essa articulação, escreve Yoani:

Como el estornudo de una gripe deseada, la blogósfera alternativa cubana no deja de propagarse. Ya no se parece a ese páramo que mostraba - si acaso - unos pocas páginas con seudónimo en abril del 2007, cuando comencé con Generación Y. He perdido la cuenta de cuánto somos ahora porque cada semana me entero que han nacido, al menos, dos nuevos espacios virtuales. El bloqueo de varias plataformas bloggers y los constantes ataques sólo han servido para que el virus de la opinión libre mute hacia formas más complicadas de callar. El ADN de la expresión ciudadana no cederá ante vacunas basadas en la intimidación y la difamación: terminará por infectar a todos. ${ }^{11}$

Através da interação com outros internautas, os blogueiros propõem outra forma de comunicação potencialmente mais criativa e democrática, à medida que tais tecnologias possibilitam maior interatividade, diálogo e pluralismo de ideias na rede, dando mais visibilidade e liberdade de expressão aos sufocados pelos aparatos de controle. Na perspectiva da ciberdemocracia, o principal impacto da internet é contribuir para o enfraquecimento de grupos ditatoriais e fortalecer os princípios democráticos do livre acesso a informação, sem censura.

Os regimes e governos autoritários conseguem bloquear ou limitar o livre acesso dos cidadãos aos conteúdos informativos dos sites, dos blogs, entre outras ferramentas que possibilitam a participação 
cidadã através do ciberespaço. Entretanto, mesmo que não tenham o livre acesso direto a essas páginas, cujos conteúdos são espalhados pelas comunidades virtuais na rede, como forma de burlar as formas repressoras de censura, os internautas e cidadãos desses países podem respirar um pouco mais aliviados, pois a rede traz consigo a utopia de um mundo mais democrático e liberto das amarras do autoritarismo ditatorial. Como afirma otimista Lévy (2002, p. 64): "Isso não é bom para as ditaduras, mas é bom para a cidadania."

\section{Considerações finais}

Os blogs mantidos por internautas cubanos são ferramentas na criação da esfera pública no ciberespaço e na retomada da discussão sobre os princípios democráticos que devem reger a vida social daquele país, ao mesmo tempo em que ajudam a ampliar os espaços de discussão para a prática da cidadania. $\mathrm{Na}$ diversidade de informações e opiniões publicadas na rede, permitem o exercício da pluralidade por meio da produção e da troca de informações.

\section{As mídias digitais}

reconfiguram a esfera

pública através da

participação, ampliando a

noşão de cidadania apoiada

exclusivamente na visão

político-jurídica expressada a

partir do exercício de direitos

e deveres dos cidadãos

circunscritos em deferminado

território geográfico ov

Estado-nação.

Elas, através do acesso, da interatividade e da conexão em rede, criam novas práticas culturais, ampliando e fortalecendo os laços de pertencimento entre cidadãos com interesses comuns, favorecendo a troca de informações entre os grupos locais e globais. Assim, as práticas dos blogs, formam circuitos comunicativos, desempenhando o papel de mediadores na construção da cidadania. Portanto, os blogs podem ser entendidos como práticas cidadãs na esfera pública, na medida em que se configuram como espaço de ação comum coordenada por meio do discurso e da persuasão.

Afirmar que as tecnologias de informação e comunicação afetaram as sociedades em escala mundial parece ser consensual. Entretanto, que elas são indispensáveis ao desenvolvimento e fortalecimento da democracia, especialmente em contextos onde os regimes autoritários ditatoriais ganharam força, talvez seja uma conclusão um pouco apressada. É necessário ampliar o número de pesquisas que reflitam sobre os impactos das mídias digitais, como espaços de oxigenação de ideias e o acesso e a apropriação dos cidadãos aos conteúdos informativos veiculados nesses meios em tais contextos.

As mídias digitais podem ser instrumentos de controle e de censura dos governos ao mesmo tempo em que são utilizadas para resolver os problemas contemporâneos, ampliando a acessibilidade das informações e a democracia. Podem ser meios dialógicos importantes nos debates sobre a consolidação dos princípios democráticos e éticos das ações humanas no mundo. Contudo, isso requer um aprendizado, pois a construção das utopias, de projetos de mundo melhor com maior igualdade, liberdade, solidariedade e justiça social requer qualificação das práticas cotidianas, ações educativas ampliando a participação dos cidadãos em seus contextos.

É justamente esse intercâmbio, como postula Arendt, que permite ao mundo se constituir como medida que transcende a vida pessoal de cada um. Em outras palavras, é dessa relação discursiva com os outros que emerge uma noção coletiva de realidade, diferente daquela que, na ausência de uma esfera pública, se vê obrigada a apoiarse apenas na própria subjetividade e na experiência singular. A blogosfera cubana liberta, pois, os cidadãos daquele país da prisão dessa existência integralmente privada, abrindo-lhes as portas para a construção de um mundo comum, compartilhado de significações, a partir da sociabilidade que é regida pela pluralidade e pela diversidade. A formação de uma cibercultura no ciberespaço, como afirma Quéau (2001), não é um mero domínio das técnicas de navegação proporcionado pelos recursos da informação e da comunicação, pressupõe a construção de cultura conectada ao universal, ao mundial, a um governo global. 


\section{REFERÊNCIAS}

ARENDT, Hannah. Vies politiques. Paris: Gallimard, 1974.

ARENDT, Hannah. A condição bumana. Rio de Janeiro: Forense, 1981.

BOBBIO, Norberto. A Era dos direitos. São Paulo: Editora Campus, 1992.

CUBA EN BLANCO Y NEGRO. Golpear a Yoanis? Si es solo un blogger. 13 nov. 2009. Disponível em: <http:// cubabn.wordpress.com>. Acesso em: 29 jan. 2010

FLORIANI, Adriano W. ; MORIGI, Valdir J. Circuitos comunicativos e a construção da cidadania no ciberespaço; tramas de sentido em redes de weblogs. Revista Famecos: mídia, cultura e tecnologia, Porto Alegre, Edipucrs, v. 1, n. 30, p. 107-114, 2006.

GARRETÓN, Manuel A. Democracia, ciudadanía y medios de comunicación: un marco general. In: ORTIZ, Renato et al. Los medios: nuevas plazas para la democracia. Lima: Calandria, p. 102-103, 2005.

GARRETÓN, Manuel A. Democracia de Massas: jornalismo e cidadania: estudo sobre as sociedades contemporâneas e o direito dos cidadãos à informação. Porto Alegre: Edipucrs, 2005.

HOPENHAYN, Martin. América Latina desigual y descentrada. Buenos Aires: Ed. Norma, 2005.

LÉVY, Pierre. Ciberdemocracia. Lisboa: Instituto Piaget, 2002.

MARSHALL, Thomas. H. Cidadania, classe social e status. Rio de Janeiro: Zahar, 1967.

MATA, María Cristina. Comunicación y ciudadanía. Problemas teóricos-políticos de su articulación. Revista Fronteiras: estudos midiáticos. São Leopoldo: Unisinos VIII, n. 1, p. 5-15 jan./abr., 2006.

QUÉAU, Felippe. Cibercultura e info-ética. In: MORIN, Edgar. A Religação dos Saberes: o desafio do século XXI. Rio de Janeiro: Bertrand do Brasil, p. 460-480, 2001.

SÁNCHEZ, Yoani. Éramos tan pocos. 15 dez. 2009.
Disponível em: <http://www.desdecuba.com/ generaciony> Acesso em: 29 jan. 2010.

SÁNCHEZ, Yoani. Silenciar a un blogger. 12 jan. 2010. Disponível em: <http://www.desdecuba.com/ generaciony $>$ Acesso em: 29 jan. 2010.

SÁVON, Miguel Iturria. Como la luna. 8 jan. 2010. Disponível em: <http://vocescubanas.com/ anclainsular>. Acesso em 29 jan. 2010.

TELLES, Vera da Silva. Direitos sociais: afinal do que se trata? Belo Horizonte: UFMG, 2006.

TELLES, Vera da Silva. Espaço público e espaço privado na constituição do social: notas sobre o pensamento de Hannah Arendt. Tempo Social, Departamento de Sociologia/USP, São Paulo, v. 2, n.1, p. 23-48, 1990.

VIEIRA, Liszt. Cidadania e Globalização. Rio de Janeiro: Record, 2001.

\section{NOTAS}

${ }^{1}$ Os blogueiros, no entanto, encontram maneiras de burlar essa censura, conforme revela Yoani Sánchez em seu blog Generación Y, cujo acesso desde Cuba está bloqueado desde março de 2008. Ela diz contar com a solidariedade de amigos e voluntários fora da ilha para colar seus textos na rede, transcrever o que dita por telefone, traduzir os posts para 15 idiomas e enviá-los a milhões de e-mails em todo o mundo.

${ }^{2}$ Disponível em: http://www.desdecuba.com/ generaciony

${ }^{3}$ Marcados pelas escolas ao campo, os bonecos russos, as saídas ilegais e a frustração. [Tradução livre dos autores]

${ }^{4}$ Disponível em: http://vocescubanas.com/anclainsular.

${ }^{5}$ Disponível em: http://cubabn.wordpress.com

${ }^{6}$ Disponível em: http://www.desdecuba.com/ reinaldoescobar 
${ }^{7}$ Disponível em: http://www.desdecuba.com/ sin_evasion

${ }^{8}$ Atrever-me-ia a dizer que as autoridades não imaginavam que os cidadãos apelariam a um recurso planetário para se expressar. O governo controla as câmeras dos estúdios de televisão, os microfones das estações de rádio, as páginas das revistas e jornais que se localizam no território insular, mas lá em cima, longe de seu alcance, uma rede satélite - satanizada como imprescindível oferece a quem se propõe a possibilidade de 'colocar' suas opiniões de forma praticamente ilimitada. Levou tempo até que compreendessem, mas estão se dando conta. Já sabem que para silenciar a um blogger não podem usar os mesmos métodos que usaram para calar tantos jornalistas. Ninguém pode despedir esses impertinentes da web da redação, nem prometer a eles uma semana em Varadero ou um auto Lada como compensação, muito menos podem captá-los com uma viagem ao leste europeu. A um blogger, para anulá-lo, é preciso eliminá-lo ou intimidá-lo, e essa equação já começou a ser entendida pelo estado, pelo partido [...] pelo general. [Tradução livre dos autores]

${ }^{9}$ Minha amiga, como eu e tantos cubanos, pensa nas mudanças democráticas que precisa nossa ilha [...]. Minha amiga é filóloga e tem 34 anos. Já recebeu prêmios internacionais pelo seu blog, mas em Cuba é denegrida pela imprensa oficial e foi golpeada em plena via pública por ordem de um comandante reciclado em general. Seu marido também foi agredido na rua mais central de Havana. [Tradução livre dos autores]

${ }^{10}$ Ficar sabendo que haviam golpeado a Yoanis e outros compatriotas da blogosfera cubana teve um grande impacto sobre mim, raiva, indignação, e desejos de lhes arrancar a cabeça como nos filmes de terror. O que aconteceu a Yoanis foi um disparate e dos grandes. Não foi apenas uma ação contra um ser humano, foi, além disso, uma ameaça contra a liberdade de expressão de nós, cubanos. Foi uma tentativa de calar a voz que faz doer suas feridas. Não acredito que possam calar a Yoanis. Não creio que possam com ela, não creio que possam com a gente. [Tradução livre dos autores].

${ }^{11}$ Como o espirro de uma gripe desejada, a blogosfera alternativa cubana não deixa de propagar-se. Já não parece a esse páramo que mostrava - se acaso - umas poucas páginas com pseudônimo em abril de 2007, quando comece com Generación Y. Já perdi a conta de quantos somos agora, porque cada semana fico sabendo que nasceram, pelo menos, dois novos espaços virtuais. O bloqueio de várias plataformas bloggers e os constantes ataques só serviu para que o vírus da opinião livre mutou para formas mais complicadas de capar. $\mathrm{O}$ DNA da expressão cidadã não cederá diante de vacinas baseadas na intimidação e a difamação: terminará por infectar a todos. [Tradução livre dos autores] 